\title{
Detection and expression of human papillomavirus oncogenes in non-small cell lung cancer
}

\author{
MARCO CIOTTI $^{1}$, LAURA GIULIANI ${ }^{1}$, VINCENZO AMBROGI ${ }^{2}$, CORRADO RONCI $^{1}$, \\ ARRIGO BENEDETTO ${ }^{1}$, TOMMASO C. MINEO ${ }^{2}$, KARI SYRJÄNEN ${ }^{3}$ and CARTESIO FAVALLI ${ }^{1}$ \\ ${ }^{1}$ Laboratory of Clinical Microbiology and Virology; ${ }^{2}$ Department of Thoracic Surgery, \\ University of Tor Vergata; ${ }^{3}$ Unit of Cytopathology, National Centre of Epidemiology, \\ Surveillance and Promotion of Health, National Health Institute (ISS), Rome, Italy
}

Received November 15, 2005; Accepted December 28, 2005

\begin{abstract}
Human papillomavirus (HPV) has been found in lung cancer cases with variable frequency. In the present study, we analysed a series of 38 patients with non-small cell lung cancer (NSCLC) (21 paraffin-embedded archival samples and 17 fresh surgical specimens) for the presence of E6 and E7 oncogenes of HPV16, 18 and 31. Eight of the tumours were positive (21\%): six HPV16, one HPV16+18, and one HPV31. The normal tissue surrounding the HPV-positive tumour was negative for the presence of the virus. Sequencing analysis of URR, of HPV16, which was the most frequently found HPV type in our cases, showed an adenosine deletion at nucleotide 7861 (E2-binding site) in four out of six patients. Sequencing of the entire E6 and E7 genes of HPV16 showed a $\mathrm{T}$ to $\mathrm{G}$ transition at nucleotide position 350 of E6, in all examined cases. This mutation is associated to the European variant of HPV16. Analysis of E6 and E7 transcripts was performed on the six fresh surgical specimens infected by HPV16. Our study showed that all of the tumours investigated, except one, contained E6 and E7 transcripts. Only in one case could we identify an unspliced form of the E6 transcript. Our results strengthen the relationship between HPV and NSCLC and support the hypothesis that HPV infection could play a role in bronchial carcinogenesis.
\end{abstract}

\section{Introduction}

HPV is the single most important human tumour virus, and it has been estimated that some $15-20 \%$ of all human malignancies could be related to oncogenic HPV (1-4). The key oncogenic mechanisms of HPV are mediated by its ability to

Correspondence to: Dr Marco Ciotti, Laboratory of Clinical Microbiology and Virology, University of Tor Vergata, Rome, Italy E-mail: marco.ciotti@ptvonline.it

Key words: bronchial carcinoma, human papillomavirus, PCR, gene expression, RFLP, sequencing interfere with the cell-cycle and tumour suppressive functions of the cell through its oncoproteins, E6 and E7, that inactivate p53 and $\mathrm{Rb}$ proteins, respectively (3-6).

It is currently agreed that certain oncogenic types of human papillomavirus (HPV) are the prime etiological agents of carcinoma of the uterine cervix $(1,2)$. Data have accumulated implicating the involvement of HPV in squamous cell tumours at other mucosal sites such as the oral cavity, oesophagus, sinonasal tract, larynx and bronchi (2).

Lung cancer is the leading cause of cancer-related death in Western countries (7). Cigarette smoking, exposure to asbestos and environmental pollution are considered the most important risk factors for lung cancer. These risk factors cannot explain all lung cancer cases, however, and there remains a niche for other potential risk factors, as suggested several years ago (8). The possible involvement of HPV in bronchial squamous cell lesions was first suggested in 1979 by Syrjänen, who described epithelial changes in bronchial carcinomas, closely resembling those of established HPV lesions in the genital tract, e.g. exophytic and flat condylomas $(9,10)$. However, reports concerning the HPV detection in lung tumours show several discrepancies. Several studies reported the presence of HPV-DNA within tumours with variable frequency (11-18). HPV16 and 18 genotypes were the most frequently found in lung tumours. However, some other authors didn't find HPV-DNA in lung tumours and tended to exclude any associations between HPV and these tumours $(19,20)$. This negativity, however, could be due to an inadequate choice of primers or a different sensibility of the techniques used. Moreover, where PCR is concerned, we must take into account that, in the case of HPV, the integration part of the L1 gene could be lost beside the E2 gene. For this reason, the MY09/MY11 primers, usually used during the screening, could be inadequate. We must also consider that the presence of HPV in lung tissue could be due, at least in some cases, to transit via the bloodstream of the virus from other infected sites. In support of this possibility, there is evidence of HPV in the blood of women with cervical infections (21).

The aim of this study is to investigate the role of HPV in lung carcinogenesis. Considering the information reported above, we screened a series of non-small cell lung cancers (NSCLC) for the presence of E6 and E7 oncogenes and their transcripts. 
Table I. Key characteristics of the patients.

\begin{tabular}{|c|c|c|c|c|c|c|c|c|}
\hline Patients & Age & Gender & Smoker & Surgical resection & Histology & Grade & Stage & $\begin{array}{l}\text { Vascular } \\
\text { invasion }\end{array}$ \\
\hline 1 & 71 & male & yes & lobectomy & squamous & 3 & IA & no \\
\hline 2 & 56 & male & yes & lobectomy & adenocarcinoma & 3 & IA & no \\
\hline 3 & 71 & male & yes & pneumonectomy & squamous & 2 & IA & yes \\
\hline 4 & 69 & male & yes & pneumonectomy & squamous & 1 & IA & no \\
\hline 5 & 55 & male & yes & lobectomy & squamous & 2 & IA & no \\
\hline 6 & 41 & male & yes & pneumonectomy & squamous & 3 & IA & no \\
\hline 7 & 68 & male & yes & lobectomy & squamous & 1 & IA & yes \\
\hline 8 & 71 & male & yes & pneumonectomy & squamous & 2 & IA & no \\
\hline 9 & 65 & male & yes & lobectomy & adenocarcinoma & 1 & IA & yes \\
\hline 10 & 56 & male & yes & minimal & squamous & 3 & IA & no \\
\hline 11 & 49 & male & yes & pneumonectomy & squamous & 3 & IA & yes \\
\hline 12 & 53 & female & no & pneumonectomy & large cells & 3 & IA & no \\
\hline 13 & 60 & male & yes & lobectomy & adenocarcinoma & 3 & IA & no \\
\hline 14 & 49 & male & yes & pneumonectomy & adenocarcinoma & 3 & IA & yes \\
\hline 15 & 58 & male & yes & minimal & adenocarcinoma & 2 & IA & no \\
\hline 16 & 70 & male & yes & pneumonectomy & adenocarcinoma & 3 & IA & no \\
\hline 17 & 68 & male & yes & lobectomy & squamous & 2 & IA & no \\
\hline 18 & 70 & male & yes & lobectomy & squamous & 3 & IA & no \\
\hline 19 & 62 & male & yes & pneumonectomy & adenocarcinoma & 2 & IA & no \\
\hline 20 & 35 & female & yes & lobectomy & adenocarcinoma & 3 & IA & no \\
\hline 21 & 65 & male & yes & lobectomy & anaplastic & 3 & IB & yes \\
\hline 22 & 62 & female & yes & lobectomy & anaplastic & 3 & IIB & yes \\
\hline 23 & 70 & male & yes & lobectomy & anaplastic & 3 & IIB & yes \\
\hline 24 & 71 & male & yes & lobectomy & adenocarcinoma & 3 & IIB & yes \\
\hline 25 & 69 & male & no & lobectomy & adenocarcinoma & 3 & IA & yes \\
\hline 26 & 74 & male & yes & minimal & adenocarcinoma & 3 & IA & no \\
\hline 27 & 81 & female & no & lobectomy & adenocarcinoma & 2 & IA & no \\
\hline 28 & 61 & male & yes & NA & squamous & 3 & IB & no \\
\hline 29 & 76 & male & yes & lobectomy & adenocarcinoma & 2 & IA & no \\
\hline 30 & 69 & male & yes & pneumonectomy & squamous & 3 & IA & yes \\
\hline 31 & 69 & male & yes & pneumonectomy & large cells & 2 & IB & no \\
\hline 32 & 83 & male & yes & lobectomy & squamous & 2 & IA & no \\
\hline 33 & 75 & male & yes & pneumonectomy & squamous & 3 & IA & yes \\
\hline 34 & 63 & male & yes & lobectomy & adenocarcinoma & 3 & IB & yes \\
\hline 35 & 73 & male & yes & lobectomy & adenocarcinoma & 3 & IA & no \\
\hline 36 & 70 & male & yes & lobectomy & large cells & 2 & IB & yes \\
\hline 37 & 73 & male & no & lobectomy & large cells & 3 & IB & yes \\
\hline 38 & 70 & female & yes & minimal & squamous & 3 & IA & no \\
\hline
\end{tabular}

\section{Materials and methods}

Study group. The material of the present study comprises of tumour samples (21 archival paraffin-embedded biopsies and 17 fresh surgical specimens) from 38 patients with NSCLC, who had undergone radical surgical treatment for their disease at the Thoracic Surgery Department of the University Hospital of Tor Vergata (Rome, Italy). The characteristics of the patients, their lesions and treatment modalities are summarised in Table I. The mean age of the patients was 65 years (range $35-83$ ). Of the 38 patients, 33 were men and 5 were women. Smoking history was obtained from all patients at their admission, and all except 4 were smokers. Tumours were classified according to their histological type, graded according to their differentiation level and staged according to the TNM system. Altogether, 16 tumours were squamous cell 
carcinomas (SCC), 15 were adenocarcinomas (AC), 4 were large cell carcinomas (LCC) and 3 were anaplastic carcinomas (ANC). None of the subjects had received radiation or chemo-therapy prior to surgery or reported any clinical history of respiratory papillomatosis. Informed consent was obtained from all patients at the time of their enrolment. The ethics committee of the university approved the study protocol.

Specimen collection. Archival paraffin-embedded sections from 21 patients with NSCLC were investigated only for HPV-DNA. Both viral DNA and RNA were investigated in fresh tissues surgically excised from another 17 patients affected by non-small cell lung cancer. Normal tissue surrounding the tumour was used as a negative control. Two fractions of each tumour, were snap frozen in liquid nitrogen and stored at $-80^{\circ} \mathrm{C}$ until processing.

DNA and RNA extraction. Lung cancer (5- $\mu \mathrm{m}$ paraffinembedded) sections were treated with xylene to remove paraffin, digested with ATL buffer and proteinase $\mathrm{K}$ overnight at $56^{\circ} \mathrm{C}$ in a thermo-mixer, followed by DNA extraction according to the manufacturer's instructions (QIAamp DNA mini kit; Qiagen, Hilden, Germany).

Frozen specimens were also treated with ATL buffer and proteinase $\mathrm{K}$, overnight at $56^{\circ} \mathrm{C}$ and then the lysed samples were processed for DNA extraction as above. To verify the quality of extracted DNA from the surgical specimens and paraffin-embedded tissues, $5 \mu 1$ of each sample was amplified with a primer set recognizing the $\beta$-actin gene.

A second fraction of frozen cancer tissue $(50 \mathrm{mg})$ was homogenized using micropestles (Eppendorf, Italy), then $1 \mathrm{ml}$ of Trizol (Invitrogen, S.R.L., Italy) was added and total RNA was extracted following the protocol's instructions. The absence of DNA in the extracted RNA samples was checked using primers for the $\beta$-actin gene located at the exon 4-intron 5-exon 5 junction (22).

Screening for HPV-DNA positivity and HPV genotyping. The presence and genotyping of HPV in our samples was established by a PCR using primers encompassing the E6/E7 region of the most representative high risk HPV genotypes: 16, 18, 31, as described by Fujinaga et al (23). The amplified product was purified using a High Pure PCR product purification kit according to the manufacturer's instructions (Roche Diagnostics GmbH, Germany) and subjected to fragment analysis by digestion with 3 units of AvaII or RsaI in a final volume of $20 \mu \mathrm{l}$ reaction mixture, for $1 \mathrm{~h}$ at $37^{\circ} \mathrm{C}$. Digestion products were analysed on a $2 \%$ agarose gel, stained with ethidium bromide and visualised under UV light (23). The results obtained by fragment analysis have been confirmed by cloning and sequencing the amplified product as follows: $1 \mu 1$ of the E6/E7 PCR product was cloned into pGEM-Teasy vector, according to the manufacturer's instructions (Promega, Madison, USA), and sequenced with the outer primers, T7 and SP6, using the Big dye terminator v1.1 cycle sequencing kit (Applied Biosystem, Warrington, UK). The obtained sequence was matched against the sequences deposited in GenBank (nucleotide-nucleotide BLAST; http://www.ncbi.nlm.nih.gov/BLAST).
Sequencing of HPV16 URR, E6 and E7 genes. Since most of the cases were positive for HPV16, this genotype was further investigated by sequencing. A large fragment of the URR region (567-bp) of this genotype was amplified with the sense primer, SUUR16-1 (5'-ATATACTATATTTTGTAG CGCC-3'), and the antisense primer, AURR-HPV16 (5'-TT TATACTAACCGGTTTCGGTT-3'), under the following conditions: $94^{\circ} \mathrm{C}, 10 \mathrm{~min}, 1$ cycle; $94^{\circ} \mathrm{C}, 45 \mathrm{sec} ; 55^{\circ} \mathrm{C}, 45 \mathrm{sec}$; $72^{\circ} \mathrm{C}, 45 \mathrm{sec}, 35$ cycles, and a final extension step at $72^{\circ} \mathrm{C}$ for $7 \mathrm{~min}$. The amplified product was sequenced as described above.

The entire E6 and E7 genes of HPV16 were amplified with specific primers encompassing the entire sequence of these genes: HPV16E6 sense primer (5'-CGAAACCGGTTA GTATAAAAGCAGAC-3') (position 51-77 bp); reverse HPV16E6 (5'-AGCTGGGTTTCTCTACGTGTTCT-3') (position 555-533 bp); HPV16E7 sense primer (5'-CTGTAA TCATGCATGGAGATAC-3') (position 554-575 bp), and reverse HPV16E7 (5'-TAGATTATGGTTTCTGAGAACA-3') (position 862-841 bp). The PCR conditions for the HPV16E6 gene were $94^{\circ} \mathrm{C}, 10 \mathrm{~min}, 1$ cycle; $94^{\circ} \mathrm{C}, 30 \mathrm{sec} ; 65^{\circ} \mathrm{C}, 30 \mathrm{sec}$; $72^{\circ} \mathrm{C}, 30 \mathrm{sec}, 35$ cycles; and for HPV $16 \mathrm{E} 7$ were $94^{\circ} \mathrm{C}, 10 \mathrm{~min}$, 1 cycle; $94^{\circ} \mathrm{C}, 30 \mathrm{sec} ; 55^{\circ} \mathrm{C}, 30 \mathrm{sec} ; 72^{\circ} \mathrm{C}, 30 \mathrm{sec}, 35$ cycles. All amplified products were cloned and sequenced as described above.

Expression of E6 and E7 oncogenes by RT-PCR. This type of analysis was limited to the six fresh surgical specimens which harboured HPV16.

All mRNAs present in $1.5 \mu \mathrm{g}$ of total RNA extracted from HPV-positive cases were reverse transcribed with the oligo-dT primer using the Omniscript kit (Qiagen $\mathrm{GmbH}$, Germany) in a final volume of $20 \mu \mathrm{l}$. The reaction tubes were incubated at $42^{\circ} \mathrm{C}$ for $1 \mathrm{~h}$, then at $95^{\circ} \mathrm{C}$ for $5 \mathrm{~min}$, and then placed on ice. DNA contamination was excluded by amplifying the human $\beta$-actin gene as reported by Strassburg et al (22).

The presence of E6 and E7 transcripts was evaluated by a nested RT-PCR strategy as shown in Fig. 1. Primer specificity was tested using Caski cells and an HPV16 control plasmid (pMHPV16). A negative control was also included for each amplification. In experiment $\mathrm{A}$, we investigated the presence of the E7 transcript in HPV-positive patients. A first round of PCR was performed with the sense primer, SE7-1 (5'-AT GCATGGAGATACACCTAC-3'), and the antisense primer, RE7-1 (5'-TAGATTATGGTTTCTGAGAACA-3'), followed by a second round with SE7-1 and a new reverse primer, RE7-3 (5'-ACCATCTATTTCATCCTCCTCCTCT-3').

In experiment $\mathrm{B}$, we investigated the presence of the E6 transcripts. For the first round of PCR we used the sense primer, SE6-1 (5'-CACAGTTATGCACAGAGCTGC-3'), with the antisense primer, RE6 (5'-GCATGATTACAGCTG GGTTTCTCTA-3'), located at the end of the gene; position $555-535$ bp. A second round was performed using the sense primer, SE6-2 (5'-ATGTGTGTACTGCAAGCAACAG-3'), together with the RE6 antisense primer.

In experiment $\mathrm{C}$, we tried to identify the presence of a transcript containing the E6+E7 sequence. To this end we used the sense primer, SE6-1, in combination with the antisense primer, RE7-2 (5'-GAGCTGTCATTTAATTGCTC-3'). The first round of PCR $(4 \mu 1)$ was reamplified with the same 


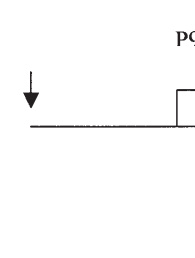

E6

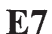

$\operatorname{Exp} \mathbf{A}$

\begin{tabular}{|c|c|c|c|c|}
\hline \multirow[b]{2}{*}{$\operatorname{Exp} \mathbf{B}$} & I round & & RE6 & \\
\hline & & SE6-2 & RE6 & \\
\hline
\end{tabular}

\begin{tabular}{|c|c|c|c|c|}
\hline \multirow[b]{2}{*}{$\operatorname{Exp} \mathbf{C}$} & & SE6-1 & RE7-2 & \multirow{2}{*}{$\begin{array}{l}514,332,215 b p \\
465,283,166 b p\end{array}$} \\
\hline & & SE6-2 & RE7-2 & \\
\hline
\end{tabular}

Figure 1. The presence of E6 and E7 transcripts was evaluated by a nested RT-PCR strategy. In experiments A and B, we looked for the presence of the E7 and E6 transcripts, respectively. The first and second vertical arrows indicate the beginning and the end of the E6 gene. The third arrow indicates the end of the E7 gene. The dashed lines delimit the spliced segment of the E6 gene. In experiment C, we investigated the presence of the E6/E7 transcript using primers encompassing the E6/E7 sequence.

Table II. Patients positive for HPV-DNA using primers specific for the E6/E7 region of HPV 16, 18 and 31.

\begin{tabular}{lcc}
\hline Patients & Histology & HPV type \\
\hline 11 & squamous & 31 \\
14 & adenocarcinoma & 16 \\
26 & adenocarcinoma & 16 \\
27 & adenocarcinoma & 16 \\
30 & squamous & $16 / 18$ \\
33 & squamous & 16 \\
34 & adenocarcinoma & 16 \\
35 & adenocarcinoma & 16 \\
\hline
\end{tabular}

antisense primer combined with a new sense primer, SE6-2 (5'-ATGTGTGTACTGCAAGCAACAG-3').

All amplification products were analysed by electrophoresis on a $2 \%$ agarose gel stained with ethidium bromide and visualised under UV light. The expected fragment sizes of the amplification products are reported in Fig. 1.

\section{Results}

Identification and sequencing of HPV-DNA. Of the 38 samples of NSCLC investigated by PCR with primers encompassing the E6/E7 region of HPV16, 18 and 31, eight were positive $(21 \%)$. In all of these cases, parallel PCR analysis of the surrounding normal tissue gave negative results. The distribution of the genotypes was as follows: six HPV16, one HPV16+18, and one HPV31 (Table II).

URR region, E6 and E7 genes of HPV16-positive cases were further investigated by sequencing and their sequences were aligned to the Seedorf sequence (GenBank accession number NC_001526) and to a control plasmid (pMHPV16), as shown in Fig. 3. The entire URR region was conserved except for an adenosine deletion at nucleotide position 7861 (E2-binding site) found in four out of six cases examined. Sequencing of the entire E6 and E7 genes didn't show any changes, except a $\mathrm{T}$ to $\mathrm{G}$ transition at position 350-bp in the E6 gene.

Detection of E6 and E7 oncogene transcripts. The study of E6 and E7 transcripts was carried out on fresh tissues of HPV16positive cases (patients 26, 27, 30, 33, 34, 35). The E6 and E7 transcripts were investigated using three PCR protocols (Fig. 1). The patterns of amplification obtained with these protocols in our patients using Caski cells as a control, were as follows: the E7 transcript was present in all cases except in patient 26 (Fig. 2).

Experiment B aimed at identifying the presence of E6 transcripts, and gave a negative result at the first round of RTPCR in all patients. In contrast, Caski cells gave the expected three bands: 414 bp referred to the unspliced transcript, and 


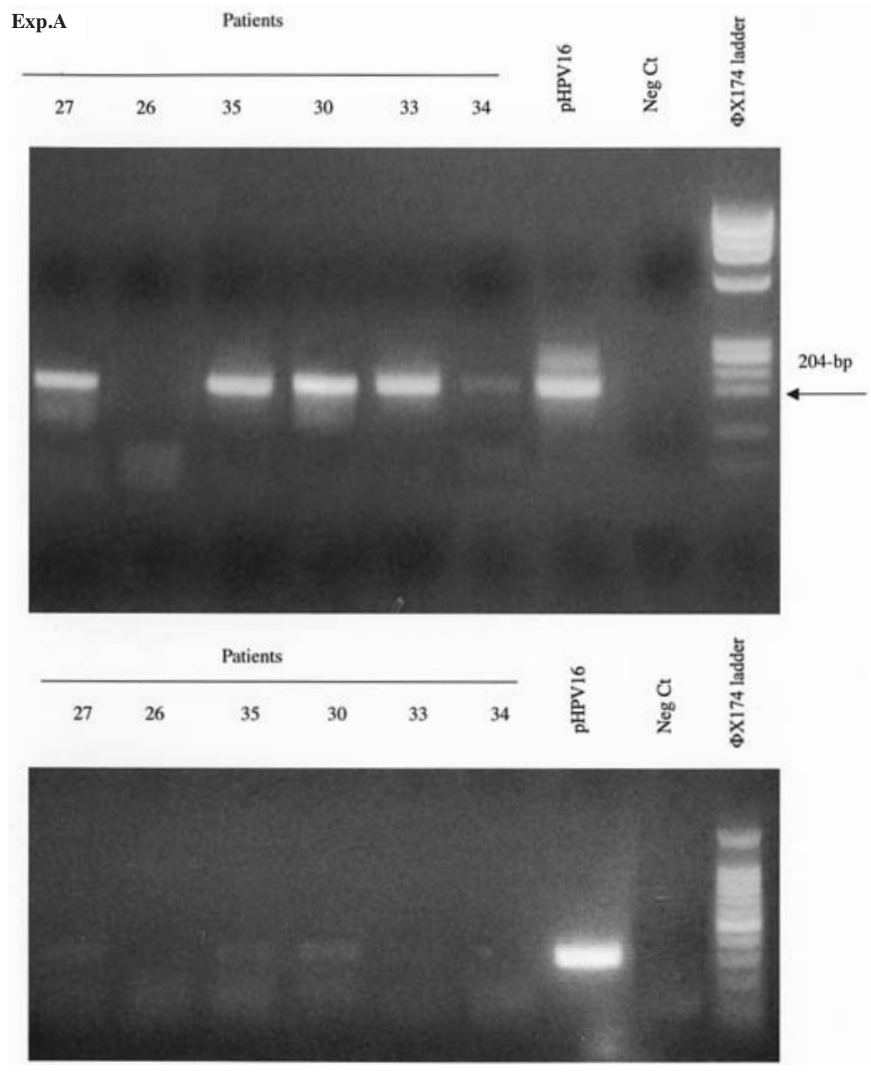

Exp.B
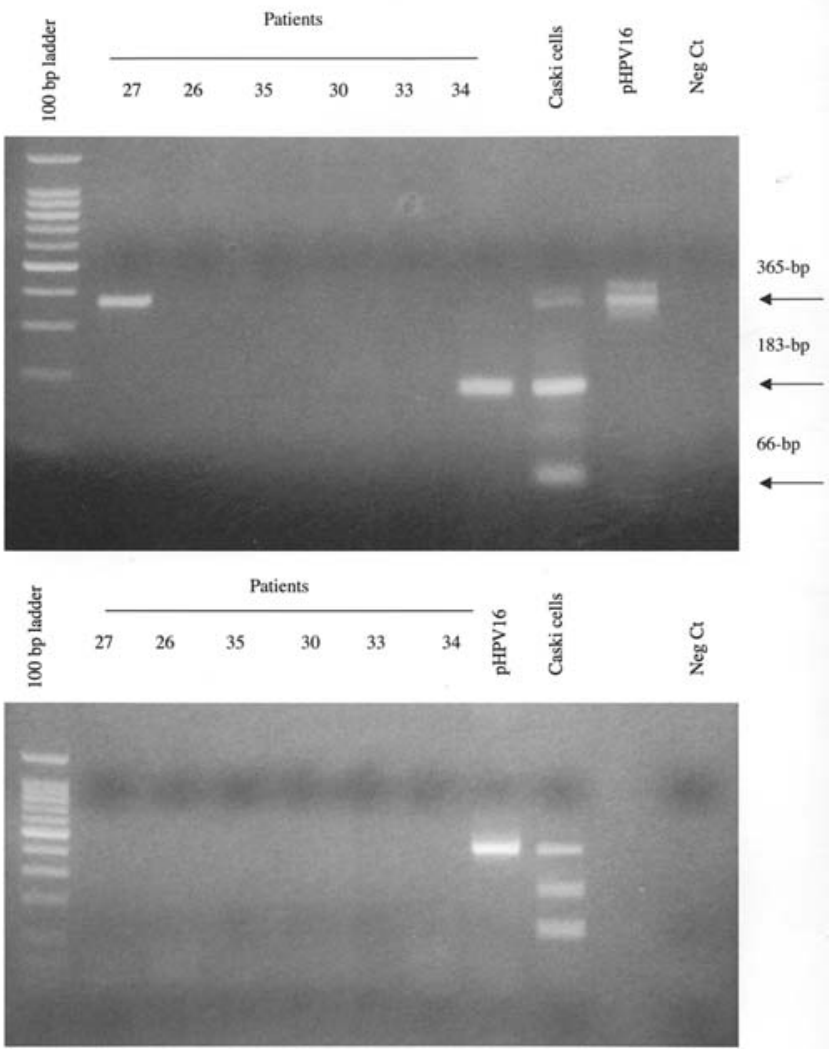

232 and 115 bp referred to E6*I and E6*II spliced isoforms, respectively. The second round of amplification was still negative in most of the patients $(26,30,33,35)$. Patients 27 and 34 showed a 365-bp unspliced form and a 183-bp E6*I isoform, respectively. Again, Caski cells showed the three expected bands of 365, 183 and $66 \mathrm{bp}$.
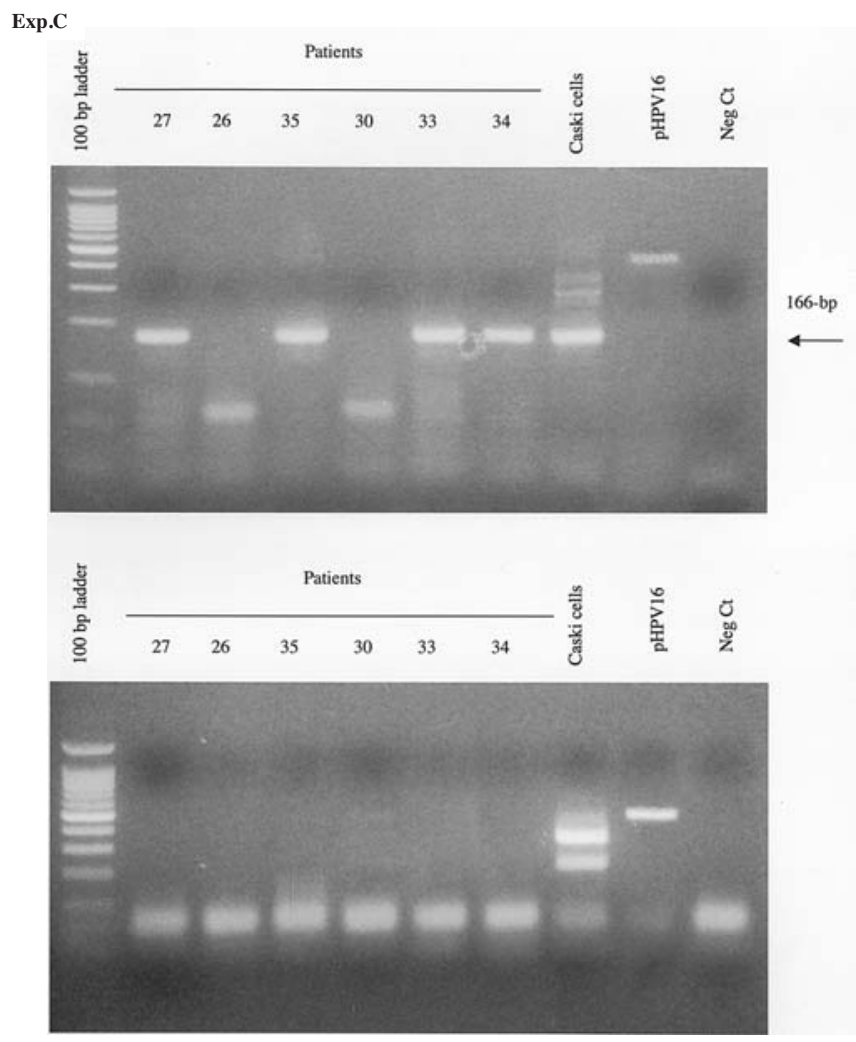

Figure 2. The results obtained with our patients and Caski cells. Experiment A: the amplification of the E7 transcript was positive in all cases except one (Exp. A, patient 27) . Experiment B aimed at identifying the presence of E6 transcripts. While the first round of RT-PCR gave a negative result in all patients, Caski cells showed three bands of the expected molecular weight: 414 bp (unspliced transcript), 232 and 115 bp referred to E6*I and E6*II spliced isoforms, respectively. In the second round, the PCR was again negative in most of the patients, except patients 27 and 34 who showed a 365-bp fragment (unspliced form) and a 183-bp band (E6*I isoform), respectively. Again, Caski cells showed the three expected bands of 365, 183 and $66 \mathrm{bp}$, respectively. Experiment $\mathrm{C}$ aimed to identify transcripts encompassing the E6/E7 region of the HPV16 genome. The first round of RT-PCR showed the presence of three bands of the expected size in the control Caski cells corresponding to the unspliced (511 bp), and spliced isoforms (332 and $215 \mathrm{bp}$ ), respectively. Patient samples were negative. A second round showed a unique band at $166 \mathrm{bp}$ in all patients except two (patients 26 and 30) corresponding to E6*I, with the control Caski cells showing a more complex pattern with a prominent band at $166 \mathrm{bp}$. A control plasmid was included in order to check the specificity of our amplifications.

In experiment $\mathrm{C}$, we tried to identify transcripts encompassing the E6/E7 region of the HPV16 genome. The first round of RT-PCR of Caski cells showed three bands of the expected size corresponding to the unspliced (511 bp), and spliced isoforms (332 and $215 \mathrm{bp}$ ), respectively. Patients' samples were negative. A second round of amplification showed a complex pattern in Caski cells with a prominent band at $166 \mathrm{bp}$. All four patients except two (patients 26 and 30) showed a unique band at 166 bp corresponding to E6*I.

\section{Discussion}

A possible role of the oncogenic types of HPV in lung oncogenesis is suggested by the presence of HPV-DNA in lung tumours (11-18). The correlation between HPV and lung cancer was particularly evident in a study of non-smoking Taiwanese 
URR

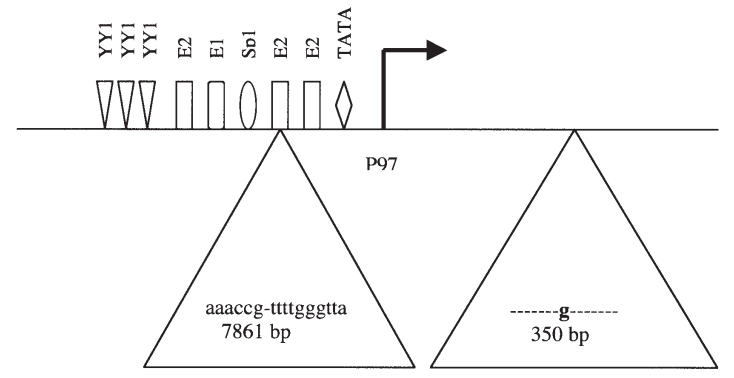

Consensus: aaaccgatttgggtta

Patient 26: aaaccg-tttgggtta Patient 27: aaaccgattttgggtta

Patient 35: aaaccg-tttgggtta

Patient 30: aaaccgattttgggtta

Patient 33: aaaccg-tttgggtta

Patient 34: aaaccg-tttgggtta

pHPV16: aaaccgatttgggtta

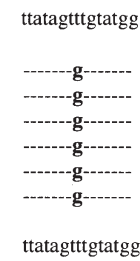

Figure 3. Sequencing results of the upstream regulatory region (547 bp) and the E6 gene of HPV16 are reported. An adenosine deletion at nucleotide position 7861 in the E2-binding site was found in four out of the six patients examined. Furthermore, all patients presented a $\mathrm{T}$ to $\mathrm{G}$ transition at nucleotide position 350 of the E6 gene. This latter mutation is typically found in the European variant of HPV16. Sequences were aligned to the reference HPV16 strain (GenBank accession number NC_001526) and to our plasmid pMHPV16.

women affected by lung cancer. In these women the detection of HPV16 and 18 using nested PCR and in situ hybridisation, was 73 and $85.5 \%$, respectively.

In the present study, we have investigated the correlation between HPV and NSCLC in a group of Italian patients, taking into consideration the following parameters: i) the presence of E6 and E7 oncogenes in tumours and their absence in surrounding normal tissue; ii) the expression of E6 and E7 oncogenes as a positive indication of viral activity in tumours.

Regarding the first point, eight of the 38 samples of NSCLC examined contained E6 and E7 genes (21\%): 6 HPV16 alone, 1 HPV16+18, and 1 HPV31. In all positive patients, the virus was present in the tumour but not in the surrounding normal tissue. The eight positive samples were represented by six fresh surgical specimens (five HPV16 and one HPV16+18) and two paraffin-embedded tissues (HPV16 and HPV31).

Sequencing of E6 showed a T to $\mathrm{G}$ transition at nucleotide position 350 resulting in an amino acid change from leucine to valine. This change is frequently found in European individuals infected by HPV16 and it has been correlated to viral persistence and increased cervical oncogenicity $(24,25)$. Interestingly, four out of six HPV16 found in our lung cancer tumours showed an adenosine deletion at nucleotide position 7861 of one of the E2-binding sites. Since this deletion is located inside the E2-binding site, an influence on E6/E7 transcription cannot be ruled out.

The expression of E6 and E7 oncogenes has been studied in six fresh surgical specimens. To our knowledge, only a study carried out by in situ hybridisation (26) faced the problem of oncogene transcription in lung tumours. The transcriptional activity of E6 and E7 oncogenes has usually been investigated in cervical cancer and HPV transformed cell lines (27-30). In these studies, the transcription process of HPV appears to be quite complex. Both the E6 and E7 oncogenes are transcribed by a common promoter (P97 in HPV16) by an alternative splicing mechanism. A common splice donor site at nucleotide 226 and two different splice acceptor sites at nucleotides 409 and 526 give rise to three different transcripts. An unspliced E6/E7 transcript encodes the E6 protein. The E7 protein is instead encoded by the splicing products, E6*I (acceptor site at nucleotide 409) and E6*II (acceptor site at nucleotide 526) (31). A novel promoter with a major start site around nucleotide 670 (P670) in the E7 ORF was identified in an HPV16 transformed cell line derived from a vulvar intraepithelial neoplasm (32).

The transcription pattern of our patients was deduced from three PCR protocols carried out in HPV16-positive patients and in control Caski cells. Amplification with primers encompassing the E7 ORF promptly showed the presence of E7 specific transcripts in five patients as well as in Caski cells. Only one patient (n. 26) was negative. A more complex pattern was obtained when the E6 transcription was investigated. The first round of RT-PCR with primers encompassing the E6 ORF gave negative results in all patients, while Caski cells showed the expected pattern of unspliced and spliced isoforms. In the second round, four patients were still negative, while patient 27 showed a 365-bp transcript (corresponding to the unspliced form of E6) and patient 34 a 183-bp transcript corresponding to the E6*I isoform. The third RT-PCR protocol carried out with primers encompassing the E6/E7 region showed a 166-bp transcript in all patients except two (patients 26 and 30). The same major band was also seen in Caski cells together with two minor additional upper bands. Interestingly, only in one case (patient 27) could we identify the unspliced form ( $365 \mathrm{bp}$ ) of E6 transcript. It is important to note that the synthesis of E6 protein is mainly derived from a bicistronic mRNA containing full-length E6 and E7 sequences (31).

In conclusion, our study showed that all tumours investigated, except one (patient 26), contained E6 and E7 RNA transcripts. The absence of viral transcripts in patient 26 could be explained by an accidental presence of HPV-DNA in the lung or by an inactive status of the virus. The latter hypothesis seems most likely since HPV-DNA was not found in the surrounding normal tissue. Collectively, our results reinforce the relationship between HPV and NSCLC and support the hypothesis that HPV infections could play a role in bronchial carcinogenesis.

\section{Acknowledgements}

The project was in part supported by Progetto speciale Ministero della Sanità - Regione Lazio 2002 (Profilo genetico associato al fenotipo metastatico ed alla prognosi dei tumori polmonari in stadio precoce).

\section{References}

1. IARC Monographs. On the evaluation of carcinogenic risks to humans. Papillomavirusus. Lyon, 1995.

2. Syrjänen $K$ and Syrjänen S: Papillomavirus Infections in Human Pathology. J Wiley \& Sons, New York, 2000.

3. Zur Hausen H: Cervical carcinoma and human papillomavirus: on the road to preventing a major human cancer. J Natl Cancer Inst 93: 252-253, 2001. 
4. Zur Hausen H: Papillomaviruses and cancer: from basic studies to clinical application. Nature Rev Cancer 2: 342-350, 2002.

5. Werness BA, Levine AJ and Howley PM: Association of human papillomavirus Types 16 and 18 E6 proteins with p53. Science 248: 76-79, 1990

6. Kessis TD, Slebos RJ, Nelson WG, Kastan MB, Plunkett BS, Han SM, Lorincz AT, Hedrick L and Cho KR: Human papillomavirus 16 E6 expression disrupts the p53-mediated cellular response to DNA damage. Proc Natl Acad Sci 90: 3988-3992, 1993.

7. Ferlay J, Bray F, Pisani P and Parkin DM: GLOBOCAN 2000: Cancer Incidence, Mortality and Prevalence Worldwide. Version 1.0. IARC Cancer Base. 5. IARC Press, Lyon, 2001.

8. Syrjänen K: Papillomavirus infections and cancer. In: Papillomaviruses and Human Disease. Syrjänen K, Gissmann L and Koss LG (eds). Springer-Verlag, Heidelberg, pp468-503, 1987.

9. Syrjanen KJ: Condylomatous changes in neoplastic bronchial epithelium. Report of a case. Respiration 38: 299-304, 1979.

10. Syrjanen KJ: Epithelial lesions suggestive of a condylomatous origin found closely associated with invasive bronchial squamous cell carcinomas. Respiration 40: 150-160, 1980.

11. Syrjanen KJ and Syrjanen SM: Human papillomavirus DNA in bronchial squamous cell carcinomas. Lancet 1: 168-169, 1987.

12. Syrjanen K, Syrjanen S, Kellokoski J, Karja J and Mantyjarvi R: Human papillomavirus (HPV) type 6 and 16 DNA sequences in bronchial squamous cell carcinomas demonstrated by in situ DNA hybridisation. Lung 167: 33-42, 1989.

13. Popper HH, el-Shabrawi Y, Wockel W, Hofler G, Kenner L, Juttner-Smolle FM and Pongratz MG: Prognostic importance of human papillomavirus typing in squamous cell papilloma of the bronchus: comparison of in situ hybridisation and the polymerase chain reaction. Human Pathol 25: 1191-1197, 1994.

14. Shamanin V, Delius H and de-Villiers EM: Development of a broad spectrum PCR assay for papillomaviruses and its application in screening lung cancer biopsies. J Gen Virol 75: 1149-1156, 1994.

15. Al-Ghamdi AA, Sanders CM, Keefe M, Coggon D and Maitland NJ: Human papillomavirus DNA and TP53 mutations in lung cancers from butchers. Br J Cancer 72: 293-297, 1995.

16. Stremlau A, Gissman L, Ikenberg H, Stark M, Bannasch P and zur Hausen H: Human papillomavirus type 16 related DNA in an anaplastic carcinoma of the lung. Cancer 55: 1737-1740, 1985.

17. Byrne JC, Tsao MS, Fraser RS and Howley PM: Human papillomavirus 11 DNA in a patient with chronic laryngotracheobronchial papillomatosis and metastatic squamous cell carcinoma of the lung. N Engl J Med 317: 873-878, 1987.

18. Noutsou A, Koffa M, Ergazaki M, Siafakas NM and Spandidos DA: Detection of human papilloma virus (HPV) and K-ras mutations in human lung carcinomas. Int J Oncol 8: 1089-1093, 1996.

19. Gorgoulis VG, Zacharatos P, Kotsinas A, et al: Human papillomavirus (HPV) is possibly involved in laryngeal but not in lung carcinogenesis. Human Pathol 30: 274-283, 1999.

20. Welt A, Hummel M, Niedobitek G and Stein H: Human papillomavirus infection is not associated with bronchial carcinoma: evaluation by in situ hybridisation and the polymerase chain reaction. J Pathol 181: 276-280, 1997.
21. Chiou HL, Wu MF, Liaw YC, Cheng YW, Wong RH, Chen CY and Lee H: The presence of human papillomavirus type 16/18 DNA in blood circulation may act as a risk marker of lung cancer in Taiwan. Cancer 97: 1558-1563, 2003.

22. Strassburg CP, Strassburg A, Nguyen N, Li Q, Manns MP and Tukey RH: Regulation and function of family 1 and family 2 UDP-glucuronosyltransferase genes (UGT1A, UGT2B) in human oesophagus. Biochem J 338: 489-498, 1999.

23. Fujinaga Y, Shimada M, Okazawa K, Fukushima M, Kato I and Fujinaga K: Simultaneous detection and typing of genital human papillomavirus DNA using the polymerase chain reaction. J Gen Virol 72: 1039-1044, 1991

24. Brady CS, Duggan-Keen MF, Davidson JA, Varley JM and Stern PL: Human papillomavirus type 16 E6 variants in cervical carcinoma: relationship to host genetic factors and clinical parameters. J Gen Virol 80: 3233-3240, 1999.

25. Zehbe I, Wilander E, Delius H and Tommasino M: Human papillomavirus 16 E6 variants are more prevalent in invasive cervical carcinoma than the prototype. Cancer Research 58: 829-833, 1998.

26. Kinoshita I, Dosaka-Akita H, Shindoh M, Fujino M, Akie K, Kato M, Fujinaga $\mathrm{K}$ and Kawakami Y: Human papillomavirus type 18 DNA and E6-E7 mRNA are detected in squamous cell carcinoma and adenocarcinoma of the lung. Br J Cancer 71: 344-349, 1995.

27. Smotkin D and Wettstein FO: Transcription of human papillomavirus type 16 early genes in a cervical cancer and a cancer-derived cell line and identification of the E7 protein. Proc Natl Acad Sci USA 83: 4680-4684, 1986.

28. Smotkin D, Prokoph H and Wettstein FO: Oncogenic and nononcogenic human genital papillomaviruses generate the E7 mRNA by different mechanisms. J Virol 63: 1441-1447, 1989.

29. Cornelissen MT, Smits HL, Briet MA, van-den TJ, Struyk AP, van-der NJ and ter SJ: Uniformity of the splicing pattern of the E6/E7 transcripts in human papillomavirus type 16-transformed human fibroblasts, human cervical premalignant lesions and carcinomas. J Gen Virol 71: 1243-1246, 1990.

30. Sotlar K, Stubner A, Diemer D, Menton S, Menton M, Dietz K, Wallwiener D, Kandolf R and Bultmann B: Detection of high-risk human papillomavirus E6 and E7 oncogene transcripts in cervical scrapes by nested RT-Polymerase chain reaction. J Med Virol 74: 107-116, 2004.

31. Stacey SN, Jordan D, Snijders PJF, Mackett M, Walboomers JMM and Arrand JR: Translation of the human papillomavirus type 16 E7 oncoprotein from bicistronic mRNA is independent of splicing events within the E6 open reading frame. J Virol 69: 7023-7031, 1995.

32. Grassmann K, Rapp B, Maschek H, Petry KU and Iftner T: Identification of a differentiation-inducible promoter in the E7 open reading frame of human papillomavirus type 16 (HPV16) in raft cultures of a new cell line containing high copy numbers of episomal HPV-16 DNA. J Virol 70: 2339-2349, 1996. 